\title{
ANALISIS PENGARUH PENAMBAHAN LIMBAH KARET TERHADAP DURABILITAS DAN FLEXIBILITAS ASPAL BETON (AC-WC)
}

\author{
Farlin Rosyad $^{l}$, Niko Prastyo ${ }^{2}$, Mudiono Kasmuri ${ }^{3}$ \\ ${ }^{1}$ Univesitas Bina Darma Palembang \\ ${ }^{2}$ Univesitas Bina Darma Palembang \\ ${ }^{3}$ Univesitas Bina Darma Palembang \\ E-mail: farlin.rosyad@binadarma.ac.id
}

\begin{abstract}
Availability of roads is an absolute prerequisite for the entry of investment into a region, for this reason it is necessary to plan strong, durable and high durability pavement for plastic deformation. Damage in Indonesia is generally caused by excessive loading. The cause of damage to this pavement requires the use of material for higher quality road pavement in the form of aggregate material as a filler and asphalt as a binder. The addition of rubber waste to the concrete asphalt mixture is a solution for highway planning and reducing pollution of rubber waste produced by rubber factories. From the results of the addition of rubber waste mixture affect the flexibility and durability of asphalt, Marshall Quotien value and residual Marshall Stability that affect flexibility and durability when compared with normal mixtures decreased, the decrease in value was due to the number of cavities in the test object mixed with rubber waste. From the results of the mixture of rubber waste produced an optimization value on Marshall stability in the percentage of $6 \%$ rubber waste of $93.68 \%$ and Marshall Quotien in the percentage of 6\% rubber waste of $272.20 \mathrm{~kg} / \mathrm{mm}$.
\end{abstract}

Keywords: Asphalt, rubber, durability, flexibility

\begin{abstract}
ABSTRAK
Ketersediaan jalan adalah prasyarat mutlak bagi masuknya investasi ke suatu wilayah, untuk itu diperlukan perencanaan perkerasan yang kuat, tahan lama dan daya tahan tinggi terhadap deformasi plastis . Kerusakan di Indonesia umumnya disebabkan oleh pembebanan yang berlebihan. Penyebab kerusakan perkerasan jalan ini menuntut penggunaan material untuk perkerasan jalan dengan kualitas yang lebih tinggi yang berupa material agregat sebagai bahan pengisi maupun aspal sebagai bahan pengikat. Penambahan limbah karet pada campuran aspal beton menjadi solusi untuk perencanaan jalan raya dan mengurangi pencemaran limbah karet yang dihasilkan dari pabrik karet. Dari hasil penambahan campuran limbah karet mempengaruhi flexibilitas dan durabilitas aspal, nilai Marshall Quotien dan Stabilitas Marshall sisa yang mempengaruhi flexibiltas dan durabilitas jika dibandingkan dengan campuran normal mengalami penurunan, penurunan nilai tersebut disebabkan karena banyaknya rongga pada benda uji yang dicampur dengan limbah karet. Dari hasil campuran limbah karet menghasilkan nilai optimasi pada stabilitas marshall pada persentase limbah karet $6 \%$ sebesar 93,68\% dan pada Marshall Quotien pada persentase limbah karet $6 \%$ sebesar 272,20 kg/mm.
\end{abstract}

Kata kunci: Aspal,karet, durabilitas, flexibilitas 


\section{PENDAHULUAN}

Jalan merupakan infrastruktur dasar dan utama dalam menggerakkan roda perekonomian nasional dan daerah, mengingat penting dan strategisnya fungsi untuk mendorong distribusi barang dan jasa sekaligus mobilitas penduduk. Ketersediaan jalan adalah prasyarat mutlak bagi masuknya investasi ke suatu wilayah. Jalan memungkinkan seluruh masyarakat mendapatkan akses pelayanan Pendidikan, kesehatan dan pekerjaan. Untuk itu diperlukan perencanaan struktur perkerasan yang kuat, tahan lama dan mempunyai daya tahan tinggi terhadap deformasi plastis yang terjadi.

Kerusakan jalan di Indonesia umumnya disebabkan oleh pembebanan yang terjadi berlebihan (overload) atau disebabkan Phiysical Damage Factor (P.D.F) berlebih, banyaknya arus kendaraan yang lewat (repetisi beban) sebagai akibat pertumbuhan jumlah kendaraan komersial dan perubahan lingkungan atau fungsi drainase kurang baik. Ketiga faktor penyebab utama kerusakan perkerasan jalan ini menuntut penggunaan material untuk perkerasan jalan (beton aspal) dengan kualitas yang lebih tinggi, yang berupa material agregat sebagai bahan pengisi maupun aspal sebagai bahan pengikat.

Perkerasan jalan yang paling banyak digunakan di Indonesia adalah lapisan aspal beton atau laston (AC/ Asphalt Concrete). Laston memiliki tingkat fleksibelitas yang tinggi sehingga penempatan langsung diatas lapisan seperti aus (AC-Wearing Course) membuat lapisan ini rentan terhadap kerusakan akibat temperature yang tinggi dan beban lalu lintas berat. Jenis kerusakan yang sering terjadi pada laston adalah pelepasan butiran dan retak. Disamping hal tersebut, kerusakan jalan juga karena terlalu tingginya viskositas aspal keras saat pencampuran dengan agregat akibat tidak berjalannya pengendalian mutu AMP sehingga temperature aspal tidak terkontrol. Penambahan aditif pada aspal menjadi alternative yang dapat digunakan untuk mempertahankan maupun meningkatkan daya rekatnya, titik lembek, maupun kelenturannya.

Dari permasalahan diatas, perlu dilakukan penelitian untuk mengetahui pengaruh Limbah Karet sebagai fraksi halus terhadap Durabilitas dan Flexibilitas Campuran Aspal Beton (AC - WC) dan pengaruh optimasi persentase penggunaan Limbah Karet terhadap Durabilitas dan Flexibilitas campuran Aspal Beton (AC - WC).

\section{METODE PENELITIAN}

Penelitian ini dilakukan di laboratorium Asphal Mixing Plan (AMP) PT. Gajah Mada Talang Taling - Palembang dengan dasar menggunakan amplop gradasi gabungan untuk campuran lapis aspal beton Asphalt Concrete - Wearing Course (AC-WC) dengan panduan standar pada spesifikasi umum Divisi 6 Bina Marga 2010.

Bahan-bahan yang akan digunakan dalam penelitian ini antara lain :

1. Agregat Kasar dan abut batu berasal dari pemacahan batu (stone crushed) dari Lingut, Martapura, OKUT.

2. Agregat halus (pasir) menggunakan pasir Tanjung Raja

3. Bahan campuran yang digunakan adalah karet hasil limbah dari pabrik karet PT. Sunan Rubber Kertapati, Kota Palembang

4. Aspal Menggunakan Aspal Penetrasi 60/70 Aspal PT. Sarana Lampung Utama 
Peralatan yang digunakan dalam penelitian ini adalah :

1. Loyang, digunakan sebagai tempat material hot bin dan agregat

2. Satu set saringan yang digunakan untuk memisahkan agregat.

3. Timbangan Triple Beam Balance, digunakan untuk menimbang berat material yang akan digunakan untuk campuran aspal

4. Alat cetak benda uji (Mould) merupakan cetakan untuk membuat briket

5. Automatic Asphalt Compactor digunakan untuk pemadatan benda uji

6. Alat-alat penunjang yang meliputi penggorengan, kompor pemanas, thermometer, sendok pengaduk, kain lap, dan spidol untuk menandai benda uji.

7. Ejektor untuk mengeluarkan benda uji setelah proses pemadatan.

Peralatan yang digunakan untuk pengujian antara lain:

1. Bak Air, untuk merendam benda uji sebelum ke tahap menggunakan water bath.

2. Water Bath (bak perendam aspal) yang di lengkapi dengan pengatur suhu.

3. Alat uji Tekan Marshall Compression Machine dilengkapi dengan flowmeter

\section{Menentukan Variasi Kadar Campuran Karet}

Memvariasikan kadar campuran karet untuk melihat pengaruhnya terhadap karakteristik campuran Laston. Pada penelitian ini campuran karet dikombinasikan menjadi 4 variasi yaitu 6\%, 8\%, 10\% campuran limbah karet dan 0\% (normal) tanpa campuran limbah karet

Tabel 1. Variasi Campuran Kadar Karet Terhadap Laston.

\begin{tabular}{|c|c|c|c|c|}
\hline Benda Uji & $\begin{array}{c}\text { Persentase } \\
\text { Limbah Karet }\end{array}$ & $\begin{array}{c}\text { Berat Limbah } \\
\text { Karet }\end{array}$ & $\begin{array}{c}\text { Jumlah } \\
\text { Spesimen }\end{array}$ & $\begin{array}{c}\text { TOTAL } \\
\text { (buah) }\end{array}$ \\
\hline Normal & $0 \%$ & 0 & 3 Briket & 3 \\
\hline Benda Uji 1 & $6 \%$ & 67,68 & 3 Briket & 3 \\
\hline Benda Uji 2 & $8 \%$ & 90,24 & 3 Briket & 3 \\
\hline Benda Uji 3 & $10 \%$ & 112,8 & 3 Briket & 3 \\
\hline \multicolumn{4}{|c|}{ Total } & 12 \\
\hline
\end{tabular}

\section{Menghitung Parameter Marshall}

Setelah melakukan pengujian benda uji dengan alat Marshall selesai, didapatkan nilai stabilitas dan flow dari bacaan pada arloji stabilitas dan marshall pada alat Marshall Compression Machine, kemudian menghitung Parameter Marshall yaitu VIM,VFB,VMA, kepadatan (density), flow, stabilitas, Marshall Quotient (MQ) sesuai parameter yang ada pada Spesifikasi campuran aspal beton AC-WC dengan menggunakan persentase campuran limbah karet 6\%, 8\%, 10\% dan 0\% (normal) terdapat pada diagram alir penelitian. 


\section{HASIL DAN PEMBAHASAN}

\section{Marshall Quotient}

Nilai Marshall Quotient yang didapat dadapat dilihat pada tabel berikut :

Tabel 2. Perbandingan Varias Persentase Limbah Karet Terhadao Marshall Quotient

\begin{tabular}{|c|c|c|}
\hline $\begin{array}{c}\text { Persentase } \\
\text { Limbah Karet }\end{array}$ & $\begin{array}{c}\text { Hasil Nilai MQ(Kg/mm) Terhadap } \\
\text { Persentase Limbah Karet }\end{array}$ & $\begin{array}{c}\text { Spesifikasi } \\
\text { (MQ) }\end{array}$ \\
\hline $0 \%$ & 311,44 & $>250$ \\
\hline $6 \%$ & 272,20 & $>250$ \\
\hline $8 \%$ & 260,25 & $>250$ \\
\hline $10 \%$ & 251,55 & $>250$ \\
\hline
\end{tabular}

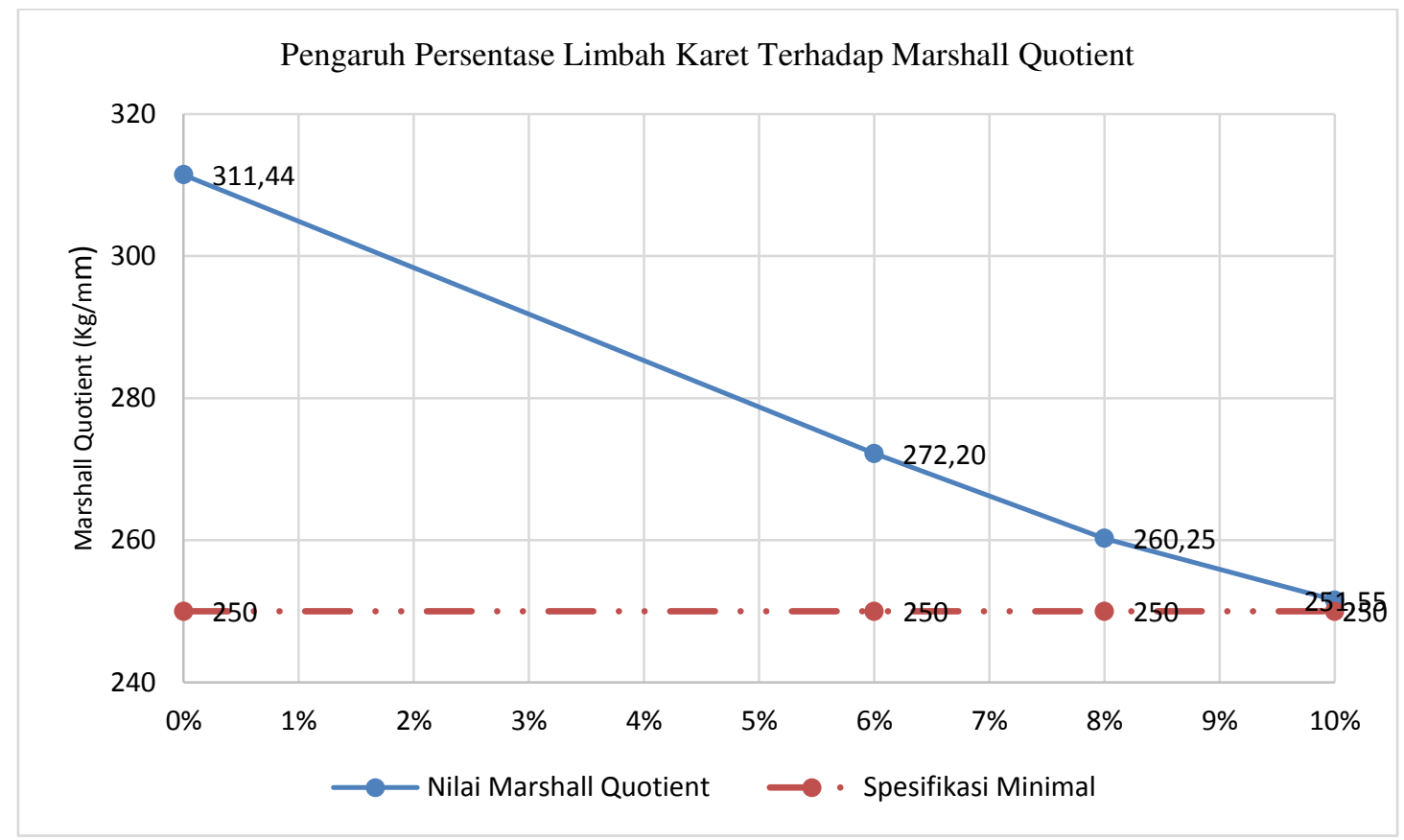

Gambar 1. Pengaruh Persentase Limbah Karet Terhadap Marshall Quotient

Dari tabel dan grafik diatas dapat disimpulkan nilai Marshall Quotient yang didapat pada campuran normal aspal beton AC-WC adalah sebesar $311,44 \mathrm{~kg} / \mathrm{mm}$ nilai tersebut memenuhi spesifikasi PU Bina Marga 2010 Revisi 3. Untuk nilai Marshall Quotient terhadap persentase limba karet $6 \%$ jika dibandingkan dengan campuran aspal normal, nilainya mengalami penurunan dengan nilai sebesar $272,20 \mathrm{~kg} / \mathrm{mm}$.. Pada persentase limbah karet $8 \%$ mengalami penurunan dengan nilai sebesar $260,25 \mathrm{~kg} / \mathrm{mm}$ dan persentase limbah karet $10 \%$ mengalami penurunan dengan nilai sebesar $251,55 \mathrm{~kg} / \mathrm{mm}$ jika dibandingkan dengan nilai campuran normal. Dilihat dari grafik nilai MQ cenderung mengalami penurunan semakin besar persentase limbah karet semakin menurun nilai MQ, nilai MQ terkecil terjadi pada persentase limbah karet 10\% dengan nilai MQ sebesar 251,55 kg/mm, nilai tersebut memenuhi spesifikasi PU Bina Marga 2010 Revisi 3 


\section{Stabilitas Marshall Sisa}

Nilai Stabilitas Marshall Sisa yang didapat, dapat dilihat pada tabel sebagai berikut :

Tabel 3. Perbandingan Varias Persentase Limbah Karet Terhadao Stabilitas Marshall Sisa

\begin{tabular}{|c|c|c|}
\hline $\begin{array}{c}\text { Persentase } \\
\text { Limbah Karet }\end{array}$ & $\begin{array}{c}\text { Hasil Nilai MQ(Kg/mm) Terhadap } \\
\text { Persentase Limbah Karet }\end{array}$ & Spesifikasi (MQ) \\
\hline $0 \%$ & 94,84 & $>90 \%$ \\
\hline $6 \%$ & 93,68 & $>90 \%$ \\
\hline $8 \%$ & 93,65 & $>90 \%$ \\
\hline $10 \%$ & 93,62 & $>90 \%$ \\
\hline
\end{tabular}

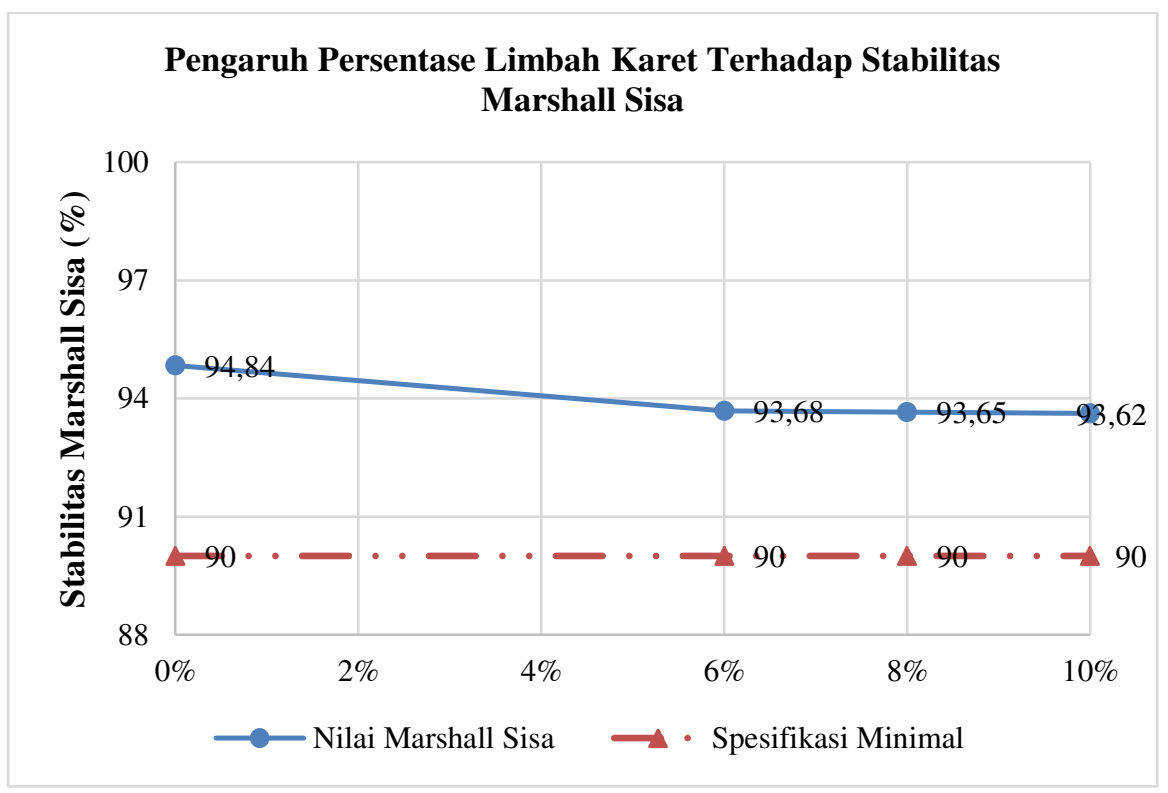

Gambar 2. Pengaruh Persentase Limbah Karet Terhadap Stabilitas Marshall Sisa.

Dari hasil dan grafik diatas dapat disimpulkan nilai Stabilitas Marshall Sisa pada campuran aspal AC-WC normal adalah sebesar 94,84\%, nilai tersebut memenuhi spesifikasi PU Bina Marga 2010 Revisi 3 nilai stabilitas marshall adalah 90\%, jika dibandingkan dengan campuran normal, persentase limbah karet 6\% stabilitas marshall sisa mengalami penurunan sebesar 93,68\%, pada persentase limbah karet $8 \%$ nilai marshall sisa yang didapat sebesar 93,65\%, nilai tersebut mengalami penurunan jika dibandingkan dengan campuran normal, sedangkan pada persentase limbah karet $10 \%$ nilai Stabilitas Marshall sisa mengalami penurunan dengan nilai sebesar 93,62\%. Nilai marshall sisa pada campuran aspal dengan persentase limbah karet cenderung mengalami penurunan, semakin besar persentase limbah karet, semakin menurun nilai marshall sisa

\section{KESIMPULAN DAN SARAN}

Dari hasil penelitian analisis pengaruh penambahan limbah karet terhadap durabilitas dan flexibilitas aspal beton (AC-WC) dapat disimpulkan bahwa, pengaruh persentase limbah karet sebagai fraksi halus terhadap durabilitas dan flexibilitas, dalam hal ini durabilitas dipengaruhi oleh Stabilitas 
Marshall Sisa dan flexibilitas di pengaruhi nilai Marshall Quotient, nilai stabilitas marshall sisa didapat nilai 94,84\% pada campuran normal, 93,68\% pada campuran limbah karet 6\%, 93,65\% pada campuran limbah karet $8 \%$ dan $93,62 \%$ pada campuran limbah karet $10 \%$ sedangkan Marshall Quotient didapat nilai 311,44 kg/mm pada campuran normal, 272,20 kg/mm pada campuran limbah karet $6 \%, 260,25 \mathrm{~kg} / \mathrm{mm}$ pada campuran limbah karet $8 \%$ dan $251,55 \mathrm{~kg} / \mathrm{mm}$ pada campuran limbah karet $10 \%$. Dapat dilihat pada tiap persentase limbah karet mengalami penurunan jika dibandingkan dengan campuran normal. Penurunan ini terjadi karena nilai VIM yang didapat mengalami peningkatan jika dibandingkan dengan nilai VIM campuran normal, sehingga mengakibatkan banyaknya rongga pada aspal campuran limbah karet. Sedangkan untuk VIM, VMA dan VFB memenuhi spesifikasi. Persentase campuran limbah karet pada aspal beton AC-WC menghasilkan nilai optimasi untuk stabilitas marshall sisa pada persentase limbah karet 6\% sebesar 93,68\% dan Persentase campuran limbah karet terhadap aspal beton AC-WC menghasilkan nilai optimasi untuk nilai Marshall Quotien sebesar 272,20 kg/mm yang didapat dari campuran limbah karet $6 \%$.

Dari hasil penelitian ini diusulkan beberapa saran yang dapat disampaikan untuk meningkatkan kinerja campuran aspal beton (AC-WC) dengan menambahkan fraksi halus berupa limbah karet yaitu, untuk meningkatkan durabilitas dan flexibilitas disarankan untuk mengkombinasikan jenis bahan fraksi halus lain dengan limbah karet untuk mendapatkan hasil yang lebih baik. Jika penelitian ini berlanjut disarankan untuk membuat Variasi Kadar Aspal dengan campuran Limbah Karet untuk mengetahui pengaruh dari limbah karet

\section{DAFTAR PUSTAKA}

[1] Amal, Andi Syaiful. (2018). Pemanfaatan Getah Karet Pada Aspal AC 60/70 Terhadap Stailitas Marshall Pada Asphalt Treated Base (ATB). http://ejournal.umm.ac.id/index.php/jmts/article/view/1111. Diakses 2 Mei 2018.

[2] Direktorat Jendral Bina Marga Kementrian Pekerjaan Umum Divisi 6 Revisi 3. (2010). Perkerasan Aspal. Direktorat Jendral Bina Marga Kementrian Pekerjaan Umum. Jakarta.

[3] Laos, Goestiawan, Wulandari dan Patmadjaja. (2018). Pengaruh Penambahan Serbuk Ban Karet Pada Campuran Laston Untuk Perkerasan Jalan Raya. http://publication.petra.ac.id/index.php/teknik-sipil/article/view/3894. Diakses 2 Mei 2018.

[4] Rancangan Standar Nasional Indonesia. (2003). Metode Pengujian Campuran Beraspal Panas Dengan Alat Marshall. RSNI-M-01-2003. Badan Standarisasi Nasional. Bandung.

[5] Subono, Vebby Permatasari. (2011). Karakteristik Marshall Campuran Asphalt Concrete (AC) Dengan Bahan Pengisi (Filler) Abu Vulkanik Gunung Merapi. Tidak diterbitkan. Fakultas Teknik Universitas Sebelas Maret. Surakarta.

[6] Sukirman, Silvia. 1999. Perkerasan Lentur Jalan Raya. Bandung. Nova.

[7] 2003. Beton Aspal Campuran Panas. Jakarta. Granit.

[8] Trsilvana, Krisna S, Djakfar dan Bowoputro. (2018). Pengaruh Penambahan Bahan Alami Lateks (Getah Karet) Terhadap Kinerja Marshall Aspal Porus. https://media.neliti.com/media/publications/117202-ID-pengaruh-penambahan-bahan-alamilateks-g.pdf . Diakses 2 Mei 2018.

[9] Wijaya, Darren, Antonius dan Rachmansyah. (2016). Studi Eksperimental Pengaruh Penambahan Zat Aditif Lateks Pada Beton Aspal Terhadap Stabilitas. Tidak diterbitkan. Fakultas Teknik Universitas Kristen Krida Wacana. Jakarta Barat. 